\title{
Apreensão Operatória de Figuras em Situações Geométricas
}

\section{Operative Apprehension of Figures in Geometric Situations}

\author{
Ana Paula Jahn*a; Vincenzo Bongiovanni ${ }^{\mathrm{b}}$ \\ ${ }^{a}$ Universidade de São Paulo, Instituto de Matemática e Estatística. SP, Brasil. \\ ${ }^{\mathrm{b}}$ Colégio Universitas Ensino Médio. SP, Brasil. \\ *E-mail: anajahn@usp.br
}

\begin{abstract}
Resumo
De grande importância para o estudo da Geometria são as figuras. O principal motivo é que na resolução de um problema, tais representações permitem, em geral, um acesso mais direto aos objetos da situação e menos custoso que um texto. Mas, muitas vezes, para resolver um problema, é necessário transformar ou modificar uma dada figura em outras, a fim de obter novos elementos que poderão levar à ideia de sua solução ou de uma prova. Essa capacidade de modificar uma figura envolve o que R. Duval denomina apreensão operatória da figura. Um tipo de modificação consiste na divisão da figura em outras subfiguras que podem ser reagrupadas para formar novas figuras. A capacidade de modificar uma figura de partida para visualizar a resolução de um problema pode ser desenvolvida e deve ser estimulada pelo professor no ensino da Matemática, em particular na Geometria. Nesse artigo, com base nos trabalhos do referido autor, apresentamos exemplos específicos que caracterizam e destacam o papel e a importância da apreensão operatória para analisar o funcionamento de uma figura na abordagem de uma situação geométrica por um sujeito. E ainda, introduzimos constructos teóricos da abordagem semiótica, a fim de realçar as possíveis influências de ambientes de Geometria Dinâmica em processos de visualização e nas representações que estudantes podem construir de conceitos e problemas geométricos nesses ambientes.
\end{abstract}

Palavras-chave: Geometria. Figuras. Apreensão Operatória. Visualização.

\begin{abstract}
Figures assume an important role in the study of Geometry. It should be emphasized, as the main reason, that such representations allow more direct access to objects of the problems, richer and less expensive than texts. Nevertheless, the figure can be seen by students, differently from what a teacher sees. Often, transforming or modifying figures in other ones is a helpful approach, and necessary to obtain new elements that may lead to the idea of a problem solution or proof. This ability to modify a figure refers to an operative apprehension of the figure. It can be mentioned that one important type of modification consists of dividing the figure into other sub figures that can be regrouped to form new shapes. The ability to modify a starting figure to visualize the solution of a problem can be developed and should be stimulated by the teacher in the teaching of Mathematics, in Geometry. This text presents and highlights the role and importance of the operative apprehension of figures based on specific examples.
\end{abstract}

Keywords: Geometry. Figures. Operative Apprehension. Visualization.

\section{Introdução}

As figuras $^{1}$ são frequentemente empregadas no ensino de Matemática e, mais particularmente, em Geometria. Mas, para que serve uma figura em um problema geométrico? Qual sua utilidade? Para Duval (1994), o emprego de figuras pode ser justificado considerando-se que elas, em geral, fornecem uma representação da situação geométrica mais fácil de ser apreendida do que um enunciado verbal. Diferente de um texto, as figuras explicitam, para cada objeto, suas relações com outros objetos da situação representada, ou seja, permitem perceber uma situação na sua globalidade e, consequentemente, podem constituir meios mais diretos de explorar diferentes aspectos dessa situação, antecipar resultados ou selecionar uma estratégia de resolução.
Mas, segundo esse mesmo autor, para muito alunos, as figuras não funcionam necessariamente como ferramentas heurísticas na resolução de problemas geométricos. O simples fato de ver uma figura parece inibir - ou mesmo excluir - um olhar mais matemático sobre ela e dois tipos de dificuldades são frequentemente observadas no ensino de Matemática, em diferentes níveis:

- "A resistência em desprender-se de formas e propriedades visualmente reconhecidas num primeiro olhar"2. A figura constitui assim um dado intuitivo, suficiente por si só, que não dá sentido a qualquer justificativa ou exigência de demonstração;

- "A incapacidade de ver em uma figura", isto é, de discernir possíveis elementos para a solução de um dado problema, o que demandaria focalizar a atenção sobre certas partes da figura, ou ainda, incrementá-la com traçados de outros

1 Referindo-se aqui à representação figural ou desenho.

2 As frases citadas correspondem à nossa tradução do original em francês. 
elementos complementares (Duval, 1994, p. 122).

Existe, assim, um hiato entre ver uma figura no sentido de sua percepção espontânea e a maneira matemática de olhar para ela. Como afirma Duval (1994, p.122), “uma aparece frequentemente como um obstáculo à outra, enquanto que, sem a primeira, a segunda não seria possível".

É preciso considerar ainda que uma figura é vista pelo aluno de forma diferente de como é vista por um professor. De fato, como afirma Hoffmann (1998), nós vemos com nossas mentes, não apenas com nossos olhos. O que vemos é moldado por nossas experiências, pelos padrões que conhecemos e até pelas diferenças nas conexões em nossos cérebros, desde nosso nascimento e durante o desenvolvimento de toda a vida em função dos aprendizados. Inclui-se aqui então os conhecimentos e percepções dos sujeitos. Professores e alunos não veem a mesma coisa em um diagrama ou uma imagem animada no computador, ou mesmo em uma equação algébrica. Diferentes alunos de uma turma não veem a mesma coisa em uma mesma situação matemática.

Esse fato e as considerações anteriores sugerem que existem diferentes apreensões possíveis de uma mesma figura. Para Duval (1994), tais apreensões não se reduzem às apreensões perceptiva e matemática mencionadas, mas sim, se ampliam a quatro tipos, cognitivamente distintos.

No que segue, em referência aos trabalhos de Duval (1994, 1995a, 1995b, 2006, 2012a, 2012b), buscamos apresentar e exemplificar essas apreensões, destacando o papel e importância delas para analisar o funcionamento de uma figura na abordagem de uma situação geométrica por um sujeito. No contexto educacional, entendemos que, com isso, podemos trazer elementos que auxiliem educadores e professores na identificação e análise de certas dificuldades dos alunos em olhar matematicamente para as figuras, de modo a constituírem verdadeiras ajudas heurísticas na resolução de problemas. E mais, pretendemos introduzir constructos teóricos da abordagem semiótica de Duval, a fim de realçar as possíveis influências de ambientes de Geometria Dinâmica em processos de visualização e nas representações que os estudantes constroem de conceitos, teoremas e problemas geométricos nesses ambientes.

\section{Diferentes Apreensões de Figuras em Situações Geométricas}

Duval (1994) destaca quatro maneiras de apreender uma figura: a apreensão perceptiva, a discursiva, a sequencial e a apreensão operatória. No que segue, por meio de exemplos, procuramos caracterizar de maneira detalhada cada uma dessas apreensões.

A apreensão perceptiva de uma figura é aquela que permite identificar ou reconhecer imediatamente uma forma ou um objeto, no plano ou no espaço. Essa identificação de formas se dá por meio de leis da Gestalt ${ }^{3}$ de organização ou por indicadores intrafigurais tais como: simetrias, contornos, convexidade, diferenças de tamanho, orientação, entre outros.

Por exemplo, a Figura 1a, para alguns sujeitos, pode representar um hexágono regular (cf. destacado na Figura 1b), com a ênfase da percepção em seu aspecto global. Mas para outros, a mesma figura pode representar um cubo em perspectiva (Figura 1c). Essa última percepção pode ser induzida pelos segmentos tracejados, os quais tiram, eventualmente, a atenção do contorno do polígono. Ou ainda, por alguma familiaridade do sujeito com imagens do tipo da Figura 1d, cujo contraste de cores pode acrescentar um efeito tridimensional.

Figura 1 - Apreensão perceptiva de uma figura: hexágono ou cubo?

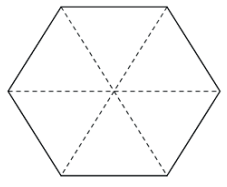

(a)
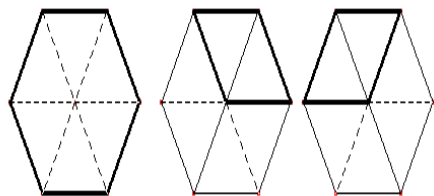

(c)

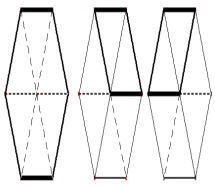

(b)

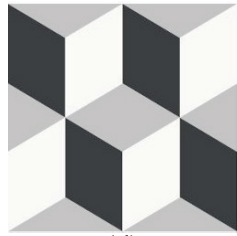

(d)
Fonte: Os Autores

Essa apreensão relativa à percepção é geralmente feita por tratamentos cognitivos automáticos da imagem pelo cérebro e, por isso, os reconhecimentos imediatos dos formatos das figuras, ou de partes que as compõem, são relativamente estáveis. Ilusões de ótica ou paradoxos de ordem visual (Figura 2) são provenientes desse tipo de apreensão.

Figura 2 - Linhas horizontais paralelas?

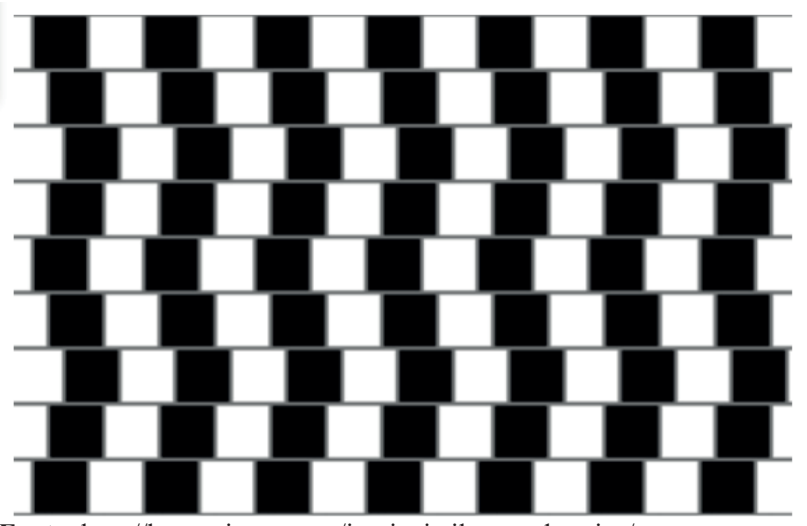

Fonte: http://hypescience.com/incriveis-ilusoes-de-otica/

Em Matemática, embora se faça constante referência à apreensão perceptiva, seja de maneira instrumental (em traçados a mão livre, com régua e compasso ou em ambientes 
de geometria dinâmica), seja mentalmente (quando muitas figuras percebidas foram interiorizadas), não se pode ficar limitado a ela, pois é relativa a um nível muito global e baseia-se apenas em constatações. De maneira geral, não se pode dizer que uma propriedade matemática "é vista" em uma figura. Concordamos com Duval (1994) quando afirma que o paralelismo de duas retas ou a congruência de dois segmentos, por exemplo, não podem ser estabelecidos nem por simples percepção, nem por medidas, pois sempre haverá margem de erro e/ou imprecisões.

Como explica o autor, referindo-se a certos tipos de tratamentos de representações figurais,

as unidades figurativas de uma figura original podem ser visualmente reconfiguradas sem qualquer recurso a uma propriedade matemática. Essa operação puramente visual de reconfigurar uma figura original está subjacente à maioria dos exemplos de evidências visuais usadas no ensino para fornecer explicações "intuitivas" de certos resultados matemáticos. Mas, na maioria dos casos, isso não funciona porque os processos visuais de reconhecimento de gestalt não funcionam da mesma maneira que o exigido ou esperado do ponto de vista matemático. (Duval, 2006, p. 112).

Com isso, outra apreensão possível é a apreensão discursiva que corresponde a uma explicitação de outras propriedades matemáticas da figura, além daquelas indicadas por uma legenda ou pelas hipóteses do enunciado. Essa explicitação é feita de maneira dedutiva, aplicando-se definições e propriedades conhecidas para deduzir outras e, assim, identificar outros elementos constitutivos da figura.

A Figura 3 exemplifica esse tipo de apreensão no caso de uma situação envolvendo um triângulo e os pontos médios de dois de seus lados.

Figura 3 - Apreensão discursiva de uma figura: identificação de outras propriedades

\begin{tabular}{|c|l|}
\hline $\begin{array}{c}\text { Dados: No triângulo } A B C, \\
A M=M B \text { e } A N=N C\end{array}$ & $\begin{array}{c}\text { Outras propriedades da } \\
\text { figura: }\end{array}$ \\
\hline & $\begin{array}{l}\text { Triângulos } A M N \text { e } A B C \\
\text { são semelhantes }(L A L), \\
\operatorname{logo} B C=2 . M N \text { e } A \widehat{M} N \\
A \hat{B} C \text { e } A \widehat{N} M \equiv A \hat{C} B\end{array}$ \\
$\mathrm{e}$, portanto, $\overline{B C} / / \overline{M N}$
\end{tabular}

Fonte: Os Autores

Cabe aqui destacar que Duval (1994) chama de figura geométrica a articulação entre a apreensão perceptiva e a apreensão discursiva. Para o autor, não há figura geométrica sem legenda ou sem um texto que a caracterize. Nesse sentido, considera-se que o desenho - ou representação figural - fica revestido de elementos relacionados ao enunciado, à sua legenda e aos conhecimentos do sujeito que o interpreta, para além dos aspectos visuais imediatos, que podem trazer ambiguidades. Exercícios ou situações que envolvem o emprego direto de teoremas ou definições referem-se a esse tipo de apreensão.

Ainda que Laborde (2005) não utilize essa mesma caracterização de "figura geométrica", ela destaca que um desenho bidimensional (em qualquer suporte) desempenha um papel ambíguo, uma vez que se refere, por um lado, a propriedades geométricas teóricas e, por outro, apresenta propriedades gráfico-espaciais que, naturalmente, dão origem a uma atividade perceptiva do aluno. Em outras palavras, a autora identifica um domínio de funcionamento do desenho, relativa ao conjunto de propriedades geométricas representadas por suas características gráfico-espaciais, e um domínio de interpretação, pois nem todas as propriedades espaciais do desenho podem ser interpretadas como propriedades geométricas do objeto representado. E nesse aspecto, converge para a ideia de Duval sobre haver um entrelaçamento entre aspectos espaciais percebidos no desenho e aspectos teóricos da Geometria, identificados nessa apreensão discursiva.

No que concerne a aprendizagem, os trabalhos da referida autora analisaram especificamente o papel das representações dinâmicas em Geometria Dinâmica e permitem mostrar que essa explicitação de propriedades matemáticas, mencionadas por Duval, é facilitada nesses ambientes, considerando que a relações geométricas aparecem como invariantes da figura sob ação do movimento (dragging). Voltaremos a essas ideias mais adiante no texto.

Outra apreensão que aparece em uma situação geométrica com representação figural é a apreensão sequencial de uma figura que corresponde ao reconhecimento da sequência de passos na construção de uma figura com a ajuda de instrumentos (régua e compasso ou software de geometria dinâmica, por exemplo). Esse tipo de apreensão, para além do domínio dos passos de construção a serem realizados, permite melhor caracterizar os objetos geométricos numa dada situação, relacionando-os às propriedades utilizadas em sua construção. Vamos dar um exemplo desse tipo de apreensão com base no seguinte problema de construção:

Construir um triângulo ABC sabendo que o lado mede 8

$\mathrm{cm}$, o ângulo $A B C$ mede $60^{\circ}$ e a mediana mede $6 \mathrm{~cm}$.

A fim de reconhecer a sequência de passos para a construção da figura, é pertinente, inicialmente, fazer um esboço da situação proposta, destacando os elementos descritos no enunciado (Figura 4).

Figura 4 - Esboço da solução do problema

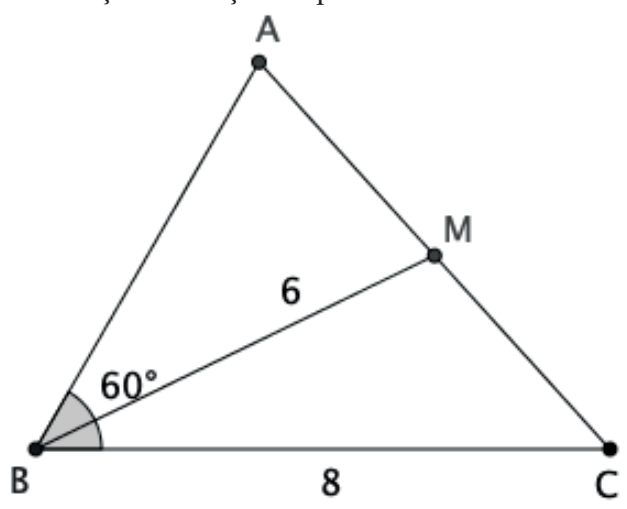

Fonte: Os Autores 
O esboço sugere começar a resolução construindo o ladoque mede $8 \mathrm{~cm}$ e o ângulo $A B C$ de medida $60^{\circ}$. Em relação à construção desse ângulo de $60^{\circ}$, é necessário o domínio dos passos de sua construção (que geralmente está associado à construção do triângulo equilátero, conforme a Proposição 1 do Livro I de "Os Elementos" de Euclides) ou seja, uma apreensão sequencial desse objeto (cf. Figura 5):

Figura 5 - Construção do ângulo de $60^{\circ}$

- Passo 1: traçar um segmento

de reta ;

- Passo 2: traçar a

circunferência de centro $B$ e raio $B C$;

- Passo 3: traçar a outra circunferência de centro $C$ e raio $C B$;

- Passo 4: criar uma intersecção das duas circunferências, nomeando-a de $A$ ';

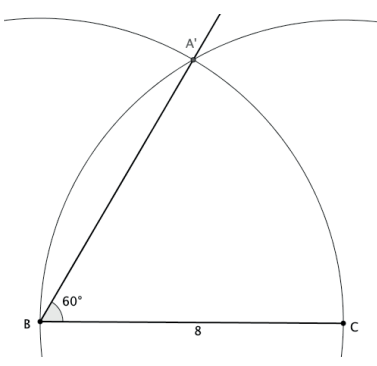

- Passo 5: traçar a semirreta

Fonte: Os Autores.

Após essa etapa, como prosseguir? Do ponto de vista do ensino, talvez esse seja um passo importante e complexo na perspectiva do aluno em situação de resolução desse problema.

É possível - no caso, necessário - explicitar outras propriedades matemáticas da figura para além daquelas indicadas no enunciado, isto é, ter uma apreensão discursiva da mesma. Uma dessas propriedades afirma que ligando os pontos médios de dois lados de um triângulo, obtém-se um segmento paralelo ao terceiro lado. Dessa forma, supondo que $N$ seja o ponto médio do lado e $M$ o ponto médio do lado , a ser construído, conclui-se que será paralelo a, conforme o esboço ilustrado na Figura 6.

Figura 6 - Apreensão discursiva da figura

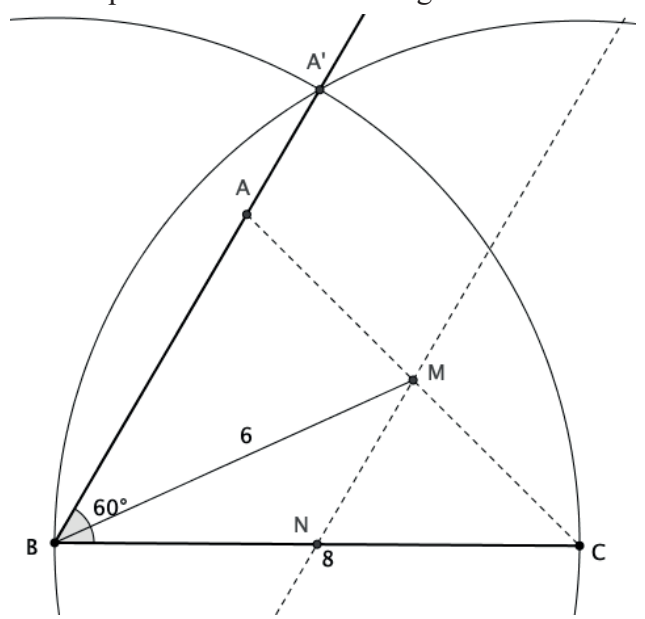

Fonte: Os Autores.

Esse resultado permite obter os próximos passos para a construção do triângulo pedido, que aparecem descritos na Figura 7.
Figura 7 - Apreensão sequencial de uma figura

- Passo 1: Construir um segmento $B C$ de medida $8 \mathrm{~cm}$;

- Passo 2: Construir um ângulo de $60^{\circ}$ de vértice $B$ e lado na semirreta

- Passo 3: Construir o ponto médio $N$ de ;

- Passo 4: Construir a reta paralela a pelo ponto $N$;

- Passo 5: Construir a circunferência de centro $B$ e raio $6 \mathrm{~cm}$;

- Passo 6: A intersecção dessa circunferência com a reta paralela será o ponto M.

- Paso 7: A reta determina, no lado do ângulo, o ponto $A$, terceiro vértice do triângulo.

Fonte: Os Autores.

A construção do triângulo proposto nesse exemplo, se inicia com a transformação de um enunciado, apresentado em língua natural, em uma representação figural - ou, nos termos de Duval (1995a), com uma atividade de conversão da representação no registro da língua natural para o registro geométrico (figural). Em seguida, uma apreensão perceptiva da figura leva a observar como iniciar a construção (construção de um segmento e de um ângulo de $60^{\circ}$ ). A construção do ângulo de $60^{\circ}$ necessita, por sua vez, de uma apreensão sequencial (associar tal ângulo aos passos de sua construção com régua e compasso). A seguir, a apreensão discursiva permite relacionar uma propriedade oculta da figura (a reta é paralela à reta ). O exemplo apresentado ilustra como se dá o processo de resolução de um problema geométrico de construção: ele vem sempre acompanhado da articulação entre diferentes apreensões da figura em jogo.

Mas, consideramos ainda que não são apenas em problemas de construção que a apreensão sequencial pode intervir. Os passos de uma construção geométrica podem ser evocados em uma situação, servindo de base para outras apreensões da figura, em particular a discursiva. Como exemplo, vamos considerar a construção de um triângulo isósceles por meio da mediatriz de sua base. O domínio dessa construção sugere a presença do eixo de simetria do triângulo isósceles (com $B$ sendo levado em $C$ e $A$ invariante) e, com isso, abre a possibilidade de identificação de outras propriedades da figura, como o fato da altura, mediana e bissetriz se confundirem. E também, sua decomposição em dois triângulos retângulos congruentes. Isso acaba por permitir um tratamento da representação figural, modificando-a e enriquecendo-a, o que se refere a outro tipo de apreensão - a operatória - de importância para o propósito desse artigo e que passamos a descrever na sequência. 


\section{Apreensão Operatória de uma Figura}

A apreensão operatória de uma figura é aquela que corresponde a transformar - modificar - a figura dada em outras figuras para obter novos elementos que poderão levar à ideia da solução de um problema ou de uma prova matemática. Essas modificações permitem acrescentar novos elementos e operar uma reorganização perceptiva da figura. Duval (1994) chama essa modificação de heuristicamente pertinente. Esse autor distingue três tipos principais de modificações possíveis:

$\left.1^{\circ}\right)$ Modificações que consistem em dividir a figura em subfiguras que podem (ou não) ser reagrupadas formando outras figuras: trata-se de uma operação de reconfiguração da figura;

$2^{\circ}$ ) Modificações que consistem no deslocamento de uma figura por uma isometria (rotação, translação, reflexão);

$3^{\circ}$ ) Modificações que consistem na ampliação, redução ou deformação de uma figura.

Essas modificações podem ser espontâneas e evidentes ou, ao contrário, difíceis de "ver" a partir da figura inicial. A cada uma dessas apreensões operatórias, correspondem tratamentos específicos das representações figurais. Na reconfiguração, por exemplo, há fatores que tornam esse tipo de operação mais ou menos visível ou mais ou menos complexo, tais como: a figura ser convexa ou não; a figura estar em suporte quadriculado ou não; alguma divisão da figura em partes elementares ser dada ou não na representação inicial.

Uma das principais tarefas na resolução de um problema é identificar possíveis modificações que trazem novos dados para avançar em sua solução e, dentre tais modificações, quais são aquelas mais pertinentes na resolução do referido problema.

No que segue, por meio de algumas situações, exemplificaremos possíveis modificações de figuras, visando destacar o papel das apreensões operatórias de figuras na resolução de problemas geométricos envolvendo representações figurais.

Cabe antes notar que existem outras abordagens que tratam desse aspectos, com denominações diferentes, como os conceitos figurais ${ }^{4}$ que, nas palavras de Fischbein (1993), podem ser pensados como conceitos e objetos e essa dualidade enfatiza as diferentes interpretações associadas às representações gráficas. Ou ainda, as configurações da Gestalt introduzidas por Acuña (2010, p. 1) que afirma:

$\mathrm{O}$ tratamento de diagramas geométricos requer $\mathrm{o}$ manuseio de aspectos figurativos do desenho, tanto quanto dos aspectos conceituais contidos na figura. Na Geometria, usamos os aspectos figurativos dos diagramas como símbolos para provar ou resolver problemas. Quando interpretamos informações figurativas, emergem o que chamamos de configurações da Gestalt: configurações figurativas auxiliares, reais ou virtuais, que dão significado e substância a uma ideia que facilita a prova ou solução do problema.

Assim, as configurações da Gestalt estão associadas ao tratamento de representações em Geometria com base em suas propriedades icônicas ou figurais, centradas na imagem visual e em sua natureza externa, materializada em algum suporte.

A autora, referindo-se a Pyke (2003), afirma que a ideia unificadora é que o gráfico (ou diagrama) é uma representação externa que se materializa através do uso de lápis e papel, computador ou outros meios e, portanto, está disponível por esses meios, em contraste com representações mentais que não são acessíveis. Na abordagem Duvaliana, a atividade cognitiva está menos centrada no visual e mais nos recursos e formas de funcionamento das representações semióticas, como pretendemos ilustrar na sequência.

\subsection{Exemplos do $1^{\circ}$ tipo de modificação em uma apreensão operatória}

Iniciamos com uma questão clássica (Figura 8), presente na maioria dos livros didáticos de Matemática do Ensino Fundamental II. Esse exercício costuma ser proposto a alunos que já têm o conhecimento de que "duas retas paralelas intersectadas por uma transversal determinam ângulos alternos internos congruentes" e de uma de suas consequências que é o fato de a "soma das medidas dos ângulos internos de um triângulo ser igual a $180^{\circ}$ ".

Figura 8 - Exemplo 1 de apreensão operatória de figura

$$
\begin{gathered}
\text { Obter a medida } x \text { do ângulo ABC representado na figura } \\
\text { abaixo. }
\end{gathered}
$$

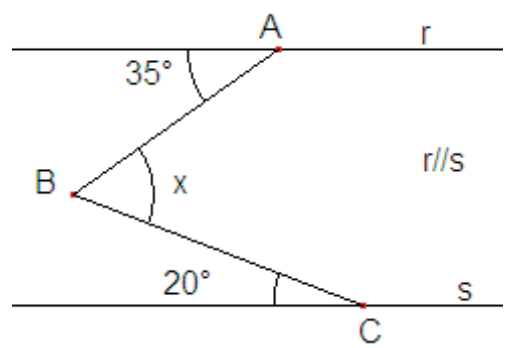

Fonte: Os Autores.

Do ponto de vista do ensino, podemos considerar que a questão não pode ser resolvida somente com a apreensão perceptiva. $\mathrm{O}$ aluno aprendeu a tratar configurações conhecidas como aquelas envolvendo triângulos, quadriláteros, polígonos ou círculos. No entanto, a configuração apresentada tem um formato não muito familiar, não evocando a propriedade citada de forma imediata. É necessário modificar a figura de partida para recair em configurações e resultados conhecidos. Uma das possíveis modificações da figura é o prolongamento da reta $A B$ de forma a interceptar a reta s no ponto $D$ (cf. Figura 9a) e obtendo o triângulo $B D C$. Esse elemento que não constava no enunciado inicial e que foi acrescido permite recair nos resultados anteriormente conhecidos pelos alunos. A partir do triângulo $B C D$, obtém-se $x=55^{\circ}$.

4 Tradução nossa do original em Inglês - figural concept - Fischbein op. cit. 
Figura 9 - Resoluções por prolongamento de retas

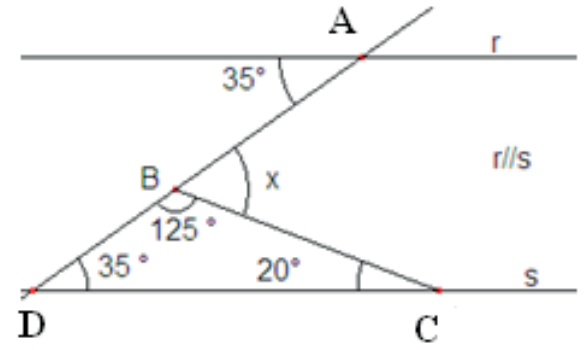

(a)

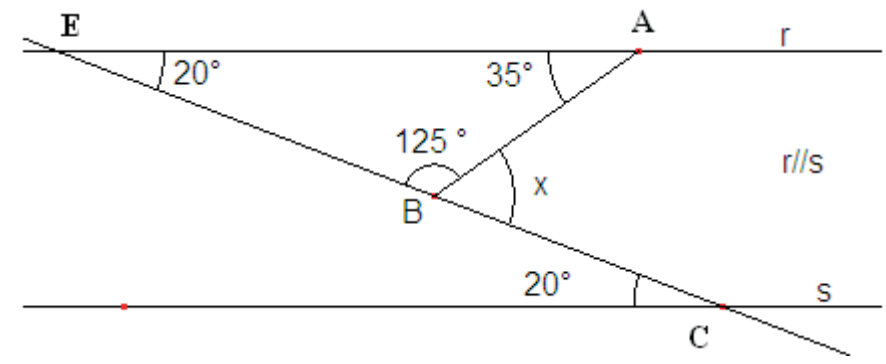

(b)

Fonte: Os Autores.

Uma outra modificação da figura inicial, similar à anterior, é o prolongamento da reta $B C$ de forma a interceptar a reta $r$ no ponto $E$ (ver Figura 9b). Novamente, recaiu-se no resultado anterior para obter $x$.

Várias outras modificações são possíveis. Por exemplo, criar dois triângulos retângulos a partir do traçado de uma reta perpendicular a $r$ pelo ponto $B$ (cf. Figura 10a). A partir dos triângulos retângulos, obtém-se $x=55^{\circ}$.

Uma modificação que também envolve o traçado de reta perpendicular é a indicada na Figura 10b: a reta perpendicular a $r$ pelo ponto $C$ determina o quadrilátero $A D C B$. Considerando que a soma das medidas dos ângulos de um quadrilátero é $360^{\circ}$, tem-se: $145^{\circ}+90^{\circ}+70^{\circ}+x=360^{\circ}$, donde $\mathrm{x}=55^{\circ}$.

Figura 10 - Resoluções por traçado de retas perpendiculares

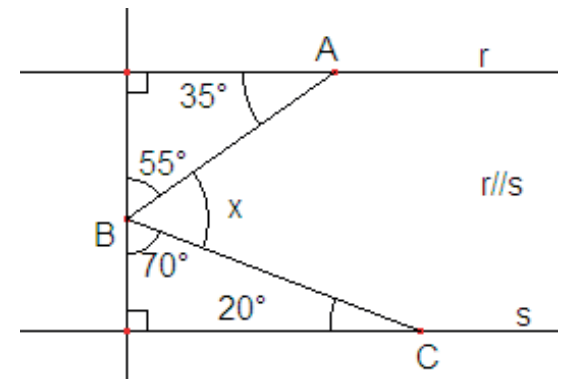

(a)

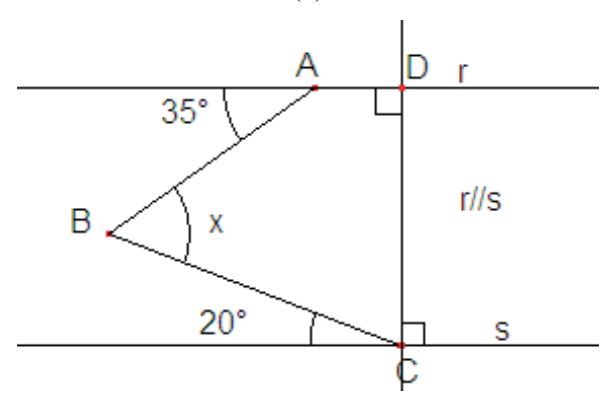

(b)

Fonte: Os Autores.

Uma quinta modificação, que pode ser motivada pela propriedade de retas paralelas cortadas por transversal, consiste na criação de uma reta paralela a $r$ pelo ponto $B$ (Figura 11). Nesse caso, para obter o valor de $x$, aplica-se duas vezes o resultado mencionado anteriormente.
Figura 11 - Resolução a partir da reta paralela a $r($ ou $s)$ por $B$.

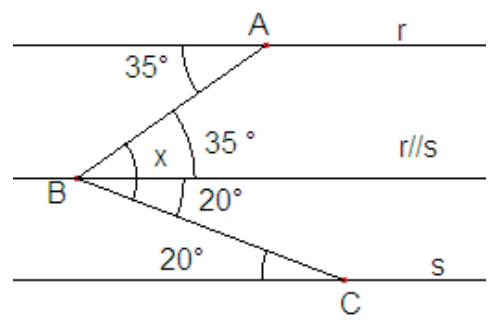

Fonte: Os Autores.

Mais uma modificação passível de ser concebida, mas que exige um certo grau de abstração, é a criação do triângulo $A B C$ (cf. Figura 12). Nessa nova configuração, há necessidade de se criar uma incógnita auxiliar $y:\left(145^{\circ}-y\right)+x+\left(y-20^{\circ}\right)$ $=180^{\circ}$, o que resulta em $x=55^{\circ}$.

Figura 12 - Resolução baseada na criação do triângulo $A B C$.

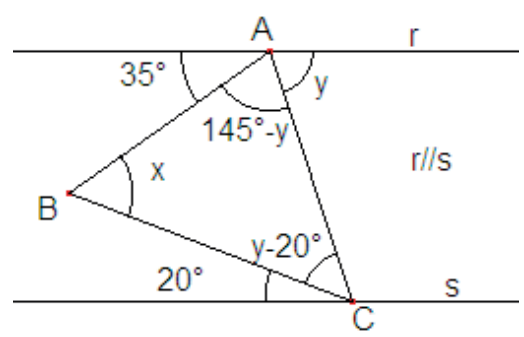

Fonte: Os Autores.

Mais uma modificação possível seria o traçado de uma reta perpendicular a $r$ pelo ponto $A$ criando-se, dessa forma, dois novos triângulos $A B E$ e $D E C$ (Figura 13). O ângulo $B \hat{A} E$ mede $55^{\circ}$, o ângulo $D \hat{E} C$ mede $70^{\circ}$, consequentemente, o ângulo $A \hat{E} B$ mede $70^{\circ}$. Logo, resulta que $x=55^{\circ}$.

Figura 13 - Resolução com apoio de reta perpendicular à $r$ (ou $s)$ passando por $A$.

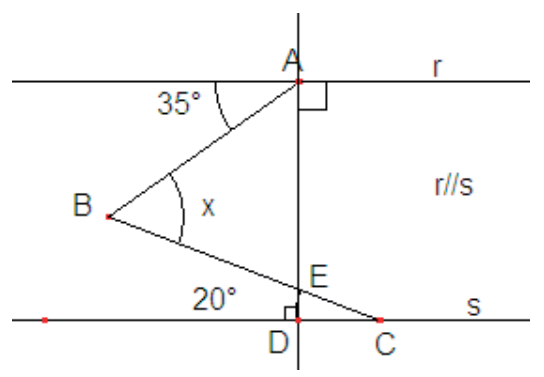

Fonte: Os Autores. 
Do ponto de vista do ensino e aprendizagem, cabe observar que a exploração de um exercício desse tipo, desafiando os alunos a encontrarem as possíveis modificações da figura que levam a uma solução, pode contribuir para eliminar a crença de que a resolução de uma questão de Geometria é única e corresponde apenas àquela esperada ou indicada pelo professor. Em outras palavras, dá a oportunidade de renegociação de regras de contrato didático, no sentido de Brousseau (1995).

Esse exemplo, com suas diferentes resoluções provenientes de modificações/transformações da figura original, permite ainda enfatizar a articulação das apreensões operatória e perceptiva caracterizando o que Duval (1994) denomina visualização de uma figura.

Na pesquisa em Educação Matemática, a visualização é geralmente referida como produto e processo de criar, usar, interpretar e refletir sobre informação visual. Parece haver consenso na comunidade dessa área de que a visualização é um componente vital da compreensão conceitual, raciocínio, resolução de problemas e prova ${ }^{5}$. Ainda que as pesquisas adotem diferentes abordagens teóricas para investigar problemáticas relacionadas aos processos de visualização ou de desenvolvimento de raciocínio espacial, como afirma Janela (2012), visualização não se reduz ao simples propósito de ilustrar uma ideia. Ao contrário, inclui "um conjunto de capacidades relacionadas com a forma como os alunos percepcionam o mundo que os rodeia, e com a sua capacidade de interpretar, modificar e antecipar transformações dos objectos" (Matos \& Gordo, 1993, p.13). Nesse sentido, observa-se conformidade com o aspecto de tratamento de representações figurais destacada na apreensão operatória ilustrada anteriormente.

A visualização, ou mais genericamente, o raciocínio espacial, parece ter reconhecida importância na Matemática e na Educação Matemática, em particular nos currículos de alguns países como Estados Unidos e Portugal. Um questionamento que foge ao escopo do artigo, mas merece ser mencionado é: será que é reconhecido também por formadores e professores que ensinam Matemática na Educação Básica?

Voltando à apreensão operatória, apresentamos um segundo exemplo com base na questão reproduzida na Figura 14, extraída de uma prova de vestibular.
Figura 14 - Exemplo 2 de apreensão operatória de figura

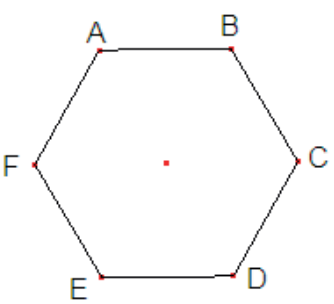

Os pontos $A, B$ e $C$ são vértices te um hexágono regular $A B C D E F$ de área igual a $16 \sqrt{3} \mathrm{~cm}^{2}$. Qual a área do triângulo $A B C$ ?

Fonte: FUVEST $^{6}$ (Fase 1, 2006), http://www.fuvest.br/.

Uma possível modificação da figura de partida, relativamente convencional, é a decomposição em 6 triângulos equiláteros a partir do centro do hexágono regular, elemento representado na figura dada no enunciado (Figura 15).

Figura 15 - Divisão da figura em 6 triângulos equiláteros

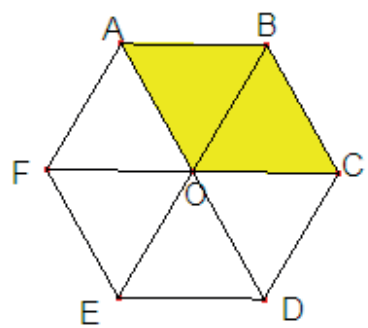

Fonte: Os Autores

A área do hexágono é $\mathrm{cm}^{2}$, portanto a área de cada triângulo equilátero é $\mathrm{cm}^{2}$. A área dos dois triângulos equiláteros $A B O \mathrm{e}$ $B C O$ será $\mathrm{cm}^{2}$, ou seja, essa área corresponde ao dobro da área do triângulo $A B C$, pois os triângulos $A B C$ e $C O A$ são congruentes. Logo, a área solicitada é $\mathrm{cm}^{2}$.

Uma outra possível modificação da figura inicial é a decomposição da figura em 3 losangos congruentes: $A B C O$, $A F E O$ e $E D C O$ (Figura 16). Como no caso anterior, a área do triângulo $A B C$ será um sexto da área do hexágono regular.

Figura 16 - Divisão da figura em 3 losangos congruentes

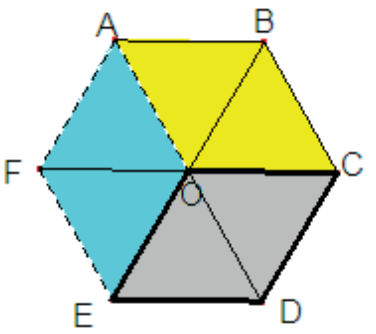

Fonte: Os Autores.

Apresentamos, a seguir, uma resolução que utiliza mais a apreensão discursiva do que a operatória. A fórmula da área do hexágono regular é utilizada para determinar a medida

5 De acordo com o documento do TSG 23 - Visualization in the teaching and learning of mathematics, ICME14. Fonte: http://www.icme14.org/static/ en/news/37.html?v=1548055625005, Acesso em 11 jul. 2019.

6 FUVEST - Fundação Universitária para o Vestibular, Universidade de São Paulo. 
do lado do hexágono e, em seguida, a determinação da área de um triângulo em função do ângulo interno. Nesse caso, a resolução é menos visual e mais técnica.

Figura 17 - Divisão do hexágono em triângulos e área em função de ângulo interno

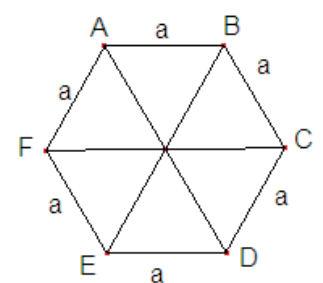

$$
\begin{aligned}
& \text { A área do hexágono } \\
& \text { regular é } 6 \cdot \frac{a^{2} \sqrt{3}}{4} \mathrm{~cm}^{2} \\
& \text { Logo, } 6 \cdot \frac{a^{2} \sqrt{3}}{4}=16 \sqrt{3} \\
& \text { Donde } a^{2}=\frac{32}{3} \mathrm{~cm}
\end{aligned}
$$

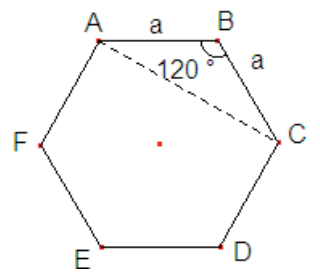

$$
\begin{aligned}
& \text { A área do triângulo } \\
& A B C \text { é } \frac{a^{2} \operatorname{sen} 120^{\circ}}{2} \\
& \text { Logo, a área é igual } \\
& \text { a: } \\
& \frac{32}{3} \cdot \frac{\operatorname{sen} 120^{\circ}}{2}=\frac{16 \sqrt{3}}{6}
\end{aligned}
$$

Fonte: Os Autores.
Nesse mesmo contexto, o exemplo a seguir foi extraído do banco de questões da Olimpíada Brasileira de Matemática das Escolas Públicas (OBMEP).

Figura 18 - Exemplo 3 de apreensão operatória de figura

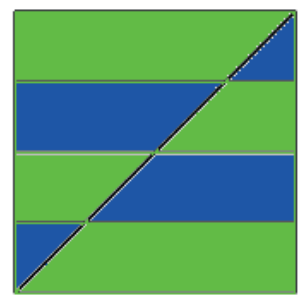

Para fazer um quadro bem moderno para sua escola, Roberto divide uma tela quadrada de $16 \mathrm{~cm}^{2}$ em 8 partes com 4 faixas de mesma largura e a diagonal, como na figura. Ele pinta o quadro de azul e verde, de modo que duas partes vizinhas tenham cores diferentes. No final, ele repara que usou mais verde do que azul. Qual a área da figura pintada de verde?

Fonte: OBMEP - Banco de Questões (2008, p. 10).

É possível solucionar o problema sem modificar a figura inicial. Nesse caso, a apreensão discursiva é que pode levar à uma resolução, como ilustrado na Figura 19.

Figura 19 - Apreensão discursiva da figura

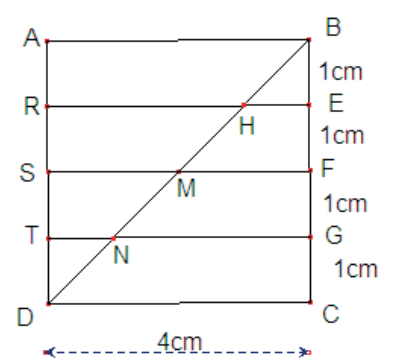

Fonte: Os Autores.

Uma outra resolução pode ser produzida modificando a figura de partida: transforma-se a figura num quadriculado 4 por 4. A figura foi dividida em 16 quadrados de área $1 \mathrm{~cm}^{2}$ cada (Figura 20). Torna-se visível que a área verde corresponde a 10 quadrados (8 quadrados completos +4 metades de quadrados). Logo a área pedida será de $10 \mathrm{~cm}^{2}$.

Figura 20 - Reconfiguração com a divisão em quadrados unitários

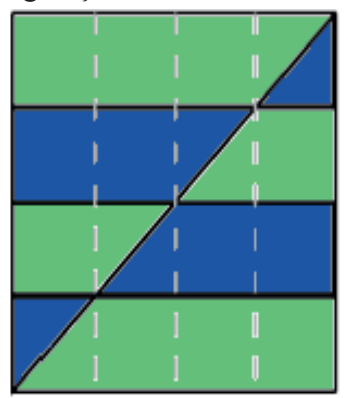

Fonte: Os Autores.

Percebe-se, nesse exemplo, que a modificação da figura introduzindo o quadriculado facilitou a resolução do problema. A divisão do quadrado inicial em um quadriculado é uma ação que caracteriza uma reconfiguração, ou seja, um tipo de apreensão operatória da figura.

Atividades de reconfiguração são recorrentes em situações geométricas envolvendo conceitos de área ou perímetro. Para finalizar essa seção, apresentamos um último exemplo dessa natureza: dadas duas circunferências de centros $Q$ e $P$ e raios $4 \mathrm{~cm}$, tangentes entre si, conforme Figura $21^{\mathrm{a}}$, pergunta-se: a que distância $d$ devemos traçar uma reta paralela a $P Q$ de modo que a área da figura pintada $A$ seja igual à área da figura pintada $B$ ?

Figura 21 - Exemplo 4 de apreensão operatória de figura

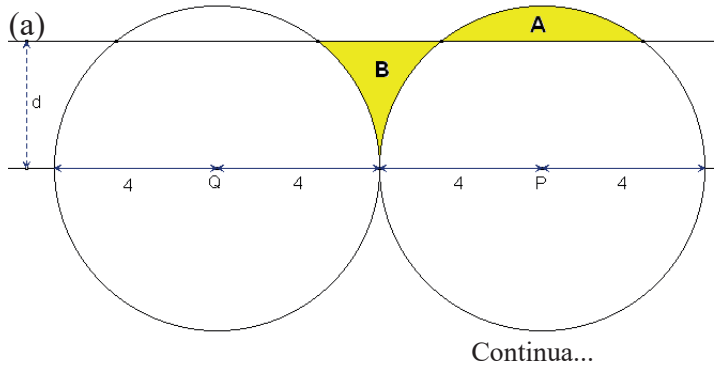


(b)

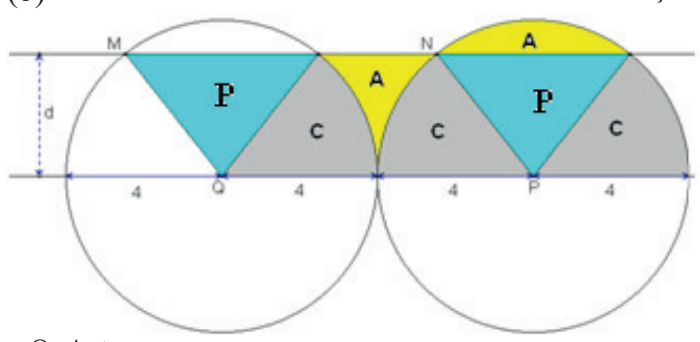

Fonte: Os Autores.

Enriquecendo a figura com alguns traçados, percebe-se visualmente que: a área do paralelogramo $M N P Q(P+C+A+C)$ deve ser igual à área do semicírculo $(C+P+A+C)$, cf. Figura $21 \mathrm{~b}$, donde se conclui que $8 d=\frac{\pi \cdot 4^{2}}{2}$ e, portanto, $d=\pi \mathrm{cm}$.

\subsection{Exemplos do $2^{\circ}$ tipo de modificação numa apreensão operatória}

São as modificações de uma figura por uma isometria. No caso abaixo (Figura 22), uma rotação da figura trará novos dados para a resolução do problema.

Figura 22- Exemplo 5 de apreensão operatória de figura

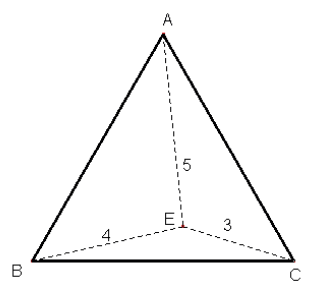

$O$ triângulo $A B C$ é equilátero. O ponto E é um ponto interior ao triângulo tal que $A E=5 \mathrm{~cm}, B E=4 \mathrm{~cm}$ e $C E=3 \mathrm{~cm}$. Obter $a$ medida do lado do triângulo $A B C$.

Fonte: Os Autores.

Uma das possíveis resoluções consiste em aplicar uma rotação, no sentido horário, do triângulo $A B C$, de um ângulo de $60^{\circ} \mathrm{em}$ torno do ponto $\mathrm{C}$ (Figura 23a).

Figura 23 - Resolução a partir da rotação da figura

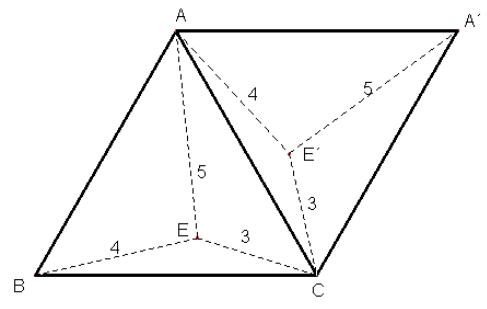

(a)

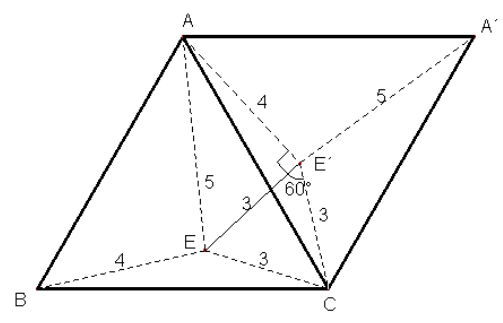

(b)
Podemos observar que o triângulo $C E E^{\prime}$ 'é equilátero e que o triângulo $A E^{\prime} E$ é retângulo em $E^{\prime}$ (lados 3,4 e $5 \mathrm{~cm}$ ). Com isso, no triângulo $A E^{\prime} C$, temos as medidas de dois lados e do angulo compreendido entre eles (Figura 23b). Aplicando o teorema dos cossenos nesse triângulo obtemos: $A C^{2}=4^{2}+3^{2}-$ 2.3.4. $\cos 150^{\circ}=16+9-24 .=25+12 . \log 0, \mathrm{~cm}$.

O exemplo a seguir trata de uma construção geométrica que utiliza uma reflexão em reta (ou simetria axial) em sua resolução.

Figura 24 - Exemplo 6 de apreensão operatória de figura Dadas duas circunferências de centros P e Q e uma reta r, obter um ponto $\mathrm{A}$ na circunferência de centro $\mathrm{P}$ e um ponto $\mathrm{B}$ na circunferência de centro $\mathrm{Q}$ de modo que $\mathrm{r}$ seja mediatriz do

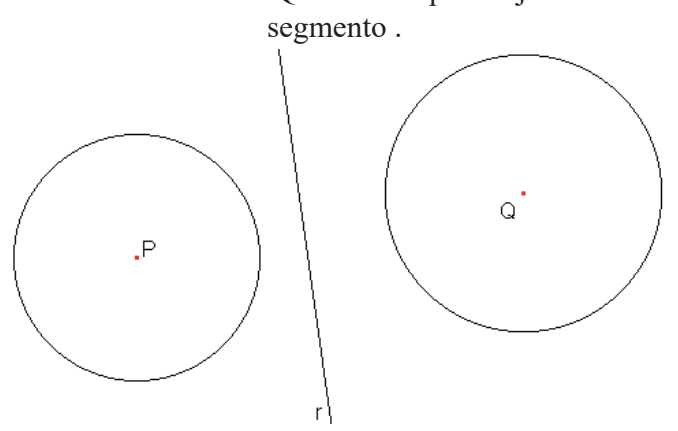

Fonte: Os Autores

Inicialmente, vamos supor o problema resolvido. Podemos observar na Figura 25a que o ponto $B$ é a imagem do ponto $A$ por uma reflexão em relação à reta $r$. Para resolver a questão, é importante mobilizar um conhecimento de uma propriedade relacionada com as transformações geométricas: "se um ponto pertence a uma circunferência, a sua imagem por uma reflexão em reta pertencerá à imagem da circunferência por essa mesma reflexão". Portanto, para obter o ponto $B$, basta refletir a circunferência de centro $P$ em relação à reta $r$ e, para isso, construir com régua e compasso o simétrico do centro e de um ponto qualquer.

A intersecção da imagem da circunferência de centro $P$ com a circunferência de centro $\mathrm{Q}$ será o ponto $\mathrm{B}$. Há várias maneiras de obter o ponto $A$. Observa-se que, com os dados da figura, o problema admite duas soluções, uma em cada semiplano determinado pela reta. Uma delas é obtida ao se traçar, pelo ponto $B$, uma perpendicular à reta $r$. Essa reta encontrará a circunferência de centro $P$ no ponto $A$ (Figura 25b).

Figura 25 - Solução obtida por meio de reflexão em reta

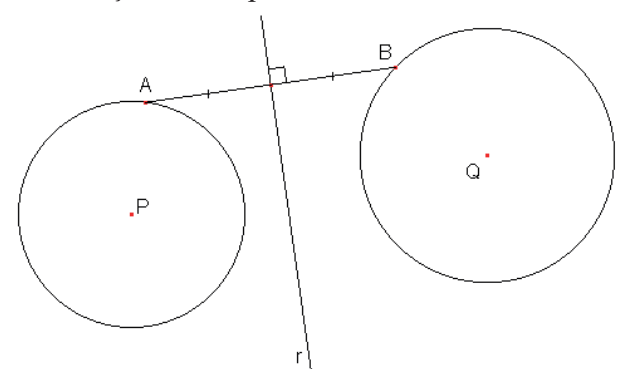

(a)

Fonte: Os Autores.

Fonte: Os Autores 


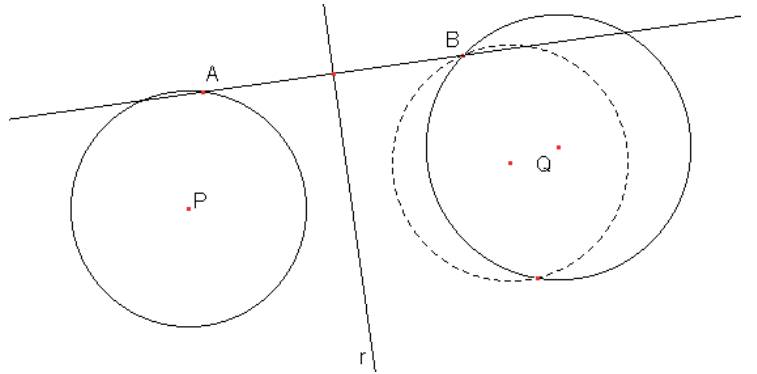

(b)

Fonte: Os Autores

\subsection{Exemplos do $3^{\circ}$ tipo de modificação numa apreensão operatória}

Tais modificações consistem na ampliação, redução ou deformação de uma figura. No caso abaixo, trata-se de uma construção geométrica que utiliza uma homotetia.

Construir um pentágono regular de lado com medida $5 \mathrm{~cm}$.

Construir um pentágono regular inscrito numa circunferência é um problema clássico cuja sequência de passos está determinada. Mas, a construção de um pentágono regular a partir da medida de um lado é um problema com maior dificuldade. Podemos usar o primeiro procedimento para construir um pentágono regular e, em seguida, transformar esse pentágono a partir de uma homotetia. Essa ampliação permitirá obter um pentágono regular de lado de medida $5 \mathrm{~cm}$.

Figura 26 - Construção de pentágono regular
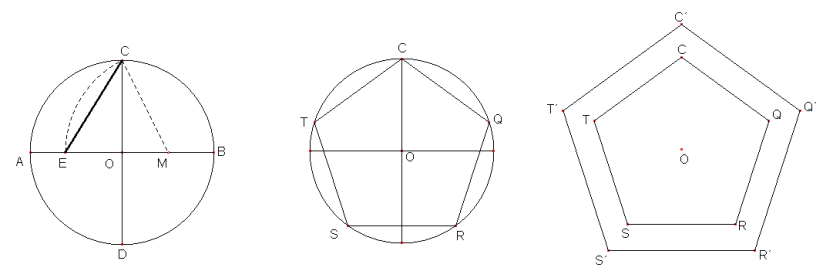

Fonte: Os Autores

A sequência de passos para construir um pentágono regular inscrito numa circunferência é:

- Passo1: Construir a circunferência de centro $O$ e raio $R$.

- Passo 2: Traçar dois diâmetros perpendiculares $A B$ e $C D$.

- Passo3: Obter o ponto médio $M$, por exemplo, do segmento .

- Passo4: Traçar uma circunferência de centro $M$ e raio (ou ).

- Passo5: A intersecção dessa circunferência com o segmento $A O$ é o ponto $E$. O lado do pentágono regular é o segmento $E C$.

Para construir um pentágono de lado $5 \mathrm{~cm}$, basta ampliar o pentágono regular construído por uma homotetia de centro $O$ e fator .

Na figura acima, CQRST é o pentágono regular inicial e C'Q'R'S'T'é o pentágono regular ampliado de lado $5 \mathrm{~cm}$.

O exemplo a seguir trata de uma transformação que deforma uma figura.
Dado um triângulo escaleno, construir a elipse de Steiner. $\underline{O b s}$ : Dizemos que uma elipse é de Steiner quando ela está inscrita num triângulo e os pontos médios dos lados do triângulo são pontos de tangência.

Inicialmente, vamos lembrar que uma afinidade de eixo $s$, direção $d$ e razão $k$, é uma aplicação do plano no plano que associa a cada ponto $P$, o ponto $P^{\prime}$ construído da seguinte maneira: pelo ponto $P$ considera-se a reta que tem a mesma direção $d$ e que intersecta $s$ no ponto $O, P^{\prime}$ é definido por, o que implica em

Figura 27 - Exemplo de Afinidade

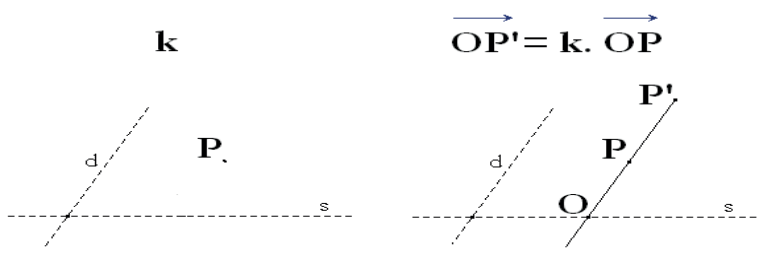

Fonte: Os Autores

Entre as propriedades de uma afinidade, podemos destacar a conservação do paralelismo, do ponto médio, do baricentro e a transformação de circunferências em elipses.

O problema trata de inscrever uma elipse num triângulo escaleno, o que não é trivial. Uma ideia é transformar a figura numa outra mais simples por meio de uma transformação geométrica, resolver o problema e, pela transformação inversa, voltar ao problema inicial. Aliás, epistemologicamente falando, essa é a caracterização inicial das transformações, que aparecem mais como método de construção para o estudo de figuras do que como objetos conceituais, como mostra Jahn (2002) em seu estudo histórico sobre o referido conceito.

$O$ fato de na Geometria afim uma circunferência ser transformada numa elipse e os pontos médios e de tangência serem invariantes, nos sugere a adoção de transformações afins como ferramentas para resolver esse tipo de problema. A passagem da Geometria Euclidiana para a Geometria afim permite uma nova entrada nas dificuldades encontradas e o funcionamento de ferramentas e técnicas não usuais na Geometria Euclidiana. A partir do triângulo dado, cria-se um triângulo equilátero e a seguir inscreve-se nele uma circunferência. Ela será tangente ao triângulo nos pontos médios dos lados. Em seguida, por uma afinidade, transformase a circunferência numa elipse.

Figura 28 - Passagem ao triângulo equilátero

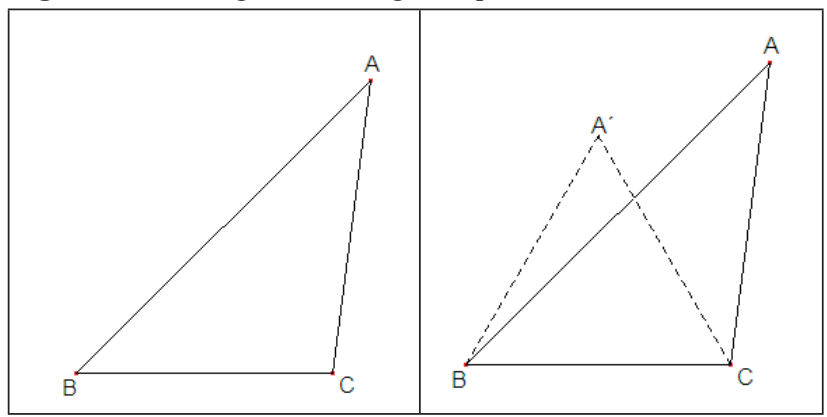

Fonte: Os Autores 
Seja $A B C$ o triângulo dado e $A^{\prime} B C$ um triângulo equilátero de base $B C$. Existirá, nesse caso, uma afinidade de eixo $B C$ e direção $A A^{\prime}$, de fator, ou seja,

Figura 29 -Transformação do triângulo $A B C$ no triângulo $A^{\prime} B C$

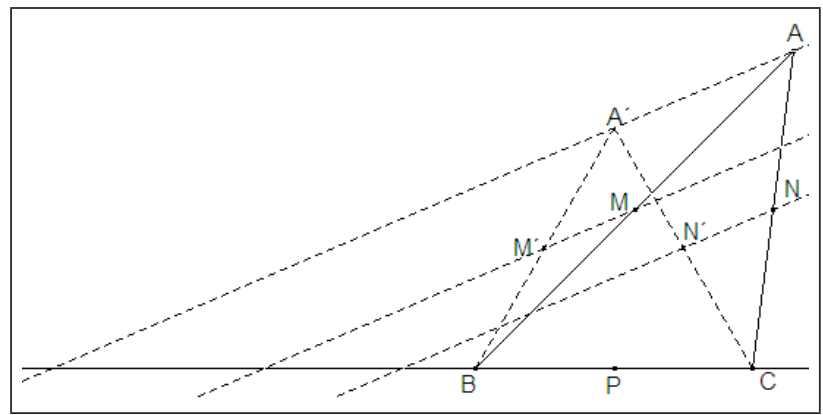

Fonte: Os Autores.

Os pontos médios $M, N$ e $P$ do triângulo $A B C$ serão, nesse caso, transformados nos pontos médios $M^{\prime}, N^{\prime}$ e $P$ do triângulo $A^{\prime} B C$. Os pontos $M^{\prime}, N^{\prime}$ e $P$ pertencem à circunferência inscrita no triângulo equilátero $A^{\prime} B C$. Logo, os pontos médios $M, N$ e $P$ são pontos da elipse inscrita no triângulo $A B C$. Como a elipse é determinada por cinco pontos, faltam determinar outros dois pontos. Escolhem-se dois pontos $R$ e $S$ da circunferência obtendo-se os correspondentes pontos $R$ ' e $S^{\prime}$ 'pela afinidade de eixo $B C$ e direção $A A^{\prime}$.

Figura 30 - Determinação dos 5 pontos da elipse

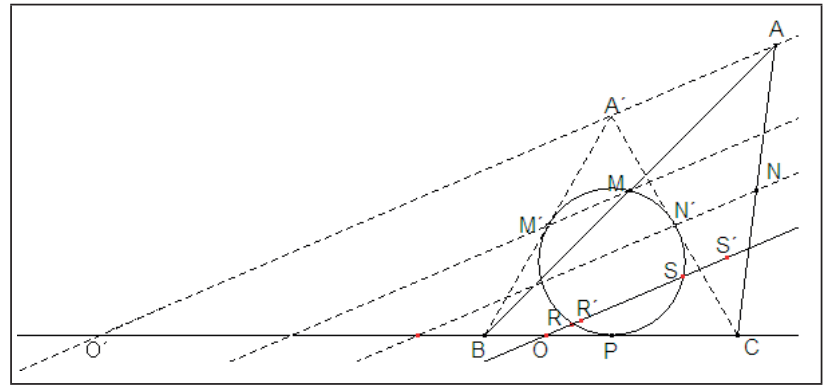

Fonte: Os Autores.

Com um software de geometria dinâmica, pode-se obter a elipse de Steiner que contém os pontos $M, N, P, R$ ' e $S$ ' (cf. Figura 31). No que segue, e com base em um exemplo, faremos considerações sobre as apreensões de figuras nesses ambientes, uma vez que estas tornam-se dinâmicas e suas propriedades geométricas características podem ser identificadas por meio da explicitação de seus elementos e, sobretudo, das relações dinâmicas entre eles.

Figura 31 - Solução do problema

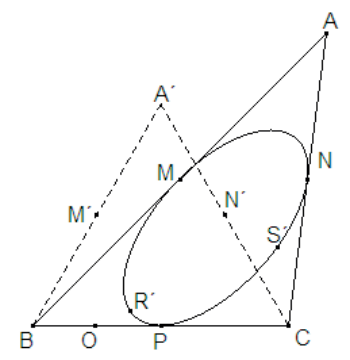

Fonte: Os Autores.

\section{Apreensões de Figuras em Ambiente de Geometria Dinâmica}

O uso da geometria dinâmica pode auxiliar no desenvolvimento de apreensões perceptivas, discursivas e operatórias de figuras. Como exemplo, vamos apresentar a seguinte atividade: imaginemos um segmento apoiado em duas retas perpendiculares e concorrentes num ponto $O$. Suponhamos que as extremidades desse segmento deslizem sobre essas retas. Que curva geométrica descreve o ponto médio $M$ desse segmento?

Inicialmente, transformamos o enunciado apresentado numa figura por meio de uma conversão de representações do registro da língua natural (de uso especializado) para o registro figural.

Figura 32 - Representação figural do problema

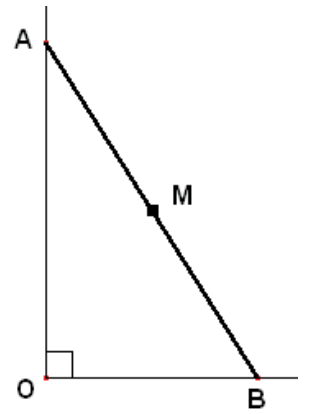

Fonte: Os Autores.

Visualizar a curva descrita pelo ponto $M$ não é tarefa muito simples, pois teremos de associar a cada posição do ponto $A$, uma posição do ponto $M$ e esse procedimento deverá ser repetido inúmeras vezes.

Figura 33 - Possíveis posições do ponto $M$

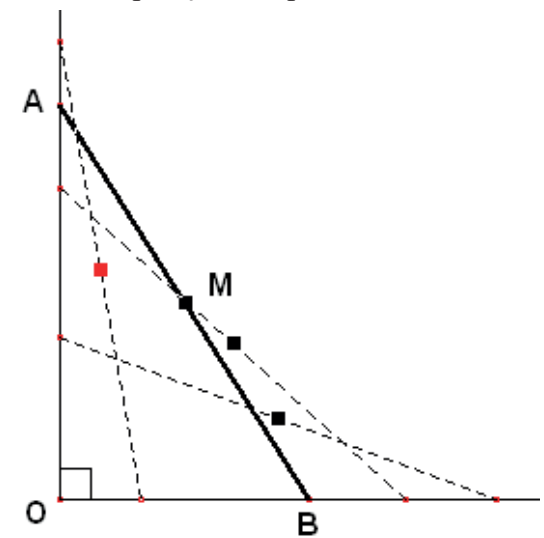

Fonte: Os Autores.

Uma outra ideia é o uso da Geometria Dinâmica (GD). O software pode ajudar a visualizar a curva. Ele apresentará de modo instantâneo o lugar geométrico do ponto $M$ quando as extremidades A e B deslizam-se nas retas $\mathrm{AO}$ e OB. A apreensão perceptiva nos dirá que a curva é um arco de circunferência. 
Figura 34 - Traçado do lugar geométrico de $M$ quando $B$ descreve a reta $O B$

Fonte: Os Autores.

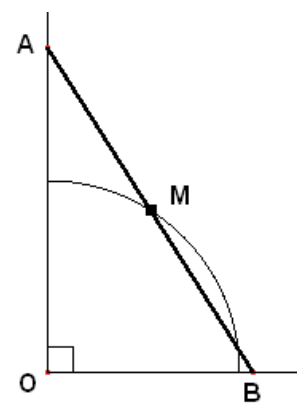

Mas, somente a apreensão discursiva da figura nos dá elementos para justificar que a curva percebida é um arco de circunferência. A propriedade geométrica em jogo é: “num triângulo retângulo, a mediana relativa à hipotenusa mede a metade da medida da hipotenusa". O segmento OM é mediana do triângulo retângulo $O A B$. Logo, a medida de $O M$ é metade da medida do segmento $A B$. Portanto, a distância do ponto $O$ ao ponto $M$ é constante, donde se conclui que a curva é um arco de circunferência de centro $O$ e raio $A B / 2$.

Nota-se que o caráter dinâmico desses ambientes concebidos para manter as relações geométricas entre os objetos - e as ferramentas nele disponíveis permitem uma exploração mais direta das figuras, favorecendo a visualização de outros elementos e de subfiguras que podem auxiliar os alunos na resolução de problemas.

\section{Conclusão}

A capacidade de modificar uma figura de partida para ter uma melhor ideia da resolução deve ser levada em conta no ensino da Geometria, pois é uma habilidade possível de ser desenvolvida pelos alunos. Para tanto, cabe ao professor construir situações de aprendizagens que levem em conta o desenvolvimento da apreensão operatória das figuras.

Os ambientes computacionais de Geometria Dinâmica (GD) podem auxiliar fortemente no desenvolvimento desse tipo de apreensão, tornando a atividade dos alunos mais experimental e exploratória, de modo a observar a figura em diversas posições, bem como incrementá-la com diversos elementos. Isso porque, para além da característica dinâmica dos objetos, estão disponíveis diversas ferramentas que representam relações e transformações geométricas e permitem, de forma bastante direta e econômica, observá-los e tratá-los com novos elementos e/ou modificações gráficoespaciais, inacessíveis no contexto do papel\&lápis.

Duval (1994) adverte que a apreensão discursiva associada à dedução e, a apreensão sequencial associada à construção, têm um fraco valor heurístico e que um trabalho com essas duas apreensões geralmente não é transferido para o desenvolvimento da apreensão operatória. Essa asserção é importante, pois mostra que valorizar apenas as construções - numa abordagem diretiva focada em passos da construção - ou as demonstrações (provas formais) é insuficiente para que os alunos tenham um bom desempenho na resolução de problemas geométricos. Faz-se necessário colocar os alunos diante de situações geométricas favoráveis à descoberta de uma solução. Tais situações não precisam ter indicações ou pistas e nem sugestões fornecidas pelo professor, mas sim, devem propiciar um trabalho focado em apreensões operatórias e visualização das figuras em jogo, trabalho este que pode ser implementado com o apoio de ambientes de $G D$, conforme ilustrado na última seção.

\section{Referências}

Acuña, C. (2010). Gestalt configurations in Geometry learning. In V. Durand-Guerrier, S. Soury-Lavergne \& F. Arzarello (Eds.), Proceedings of CERME 6 (pp. 706-715), France: INRP.

Brousseau, G. (2002) Theory of Didactical Situations in Mathematics. London: Kluwer Academic Publishers.

Duval R. (1994). Les différents fonctionnements d'une figure dans une démarche géométrique. Repères IREM, 17, 121-138.

Duval, R. (1995a) Geometrical Pictures: Kinds of representation and specific processing. In R. Suttherland and J. Mason (eds.), Exploiting Mental Imagery with Computers in Mathematics Education (pp. 142-157). Berlin: Springer.

Duval, R. (1995b). Sémiosis et pensée humaine. Berne: Peter Lang.

Duval, R. (1998), Geometry from a cognitive point a view. In C. Mammana and V. Villani (eds.), Perspectives on the Teaching of Geometry for the 21st Century, (pp. 37-52), Kluwer Academic Publishers, Dordrecht.

Duval, R. (2006). A cognitive analysis of problems of comprehension in a learning of mathematics. Educational Studies in Mathematics, 61, 103-131, Doi: 10.1007/s10649006-0400-z.

Duval, R. (2012a) Registros de representação semiótica e funcionamento cognitivo do pensamento. Revemat - Revista Eletrônica de Educação Matemática, 7(2), 266-297. doi: https://doi.org/10.5007/1981-1322.2012v7n2p266.

Duval, R. (2012b). Abordagem cognitiva de problemas de geometria em termos de congruência. Revemat - Revista Eletrônica de Educação Matemática, 7(1), 118-138.

Fischbein, E. (1993). The theory of figural concepts, Educational Studies in Mathematics, 24, 139-162.

Hoffman, D (1998). Visual intelligence: How we create what we see. New York: W. W. Norton \& Companyc.

Jahn. A.P. (2002) "Locus" and "Trace" in Cabri-géomètre: relationships between geometric and functional aspects in a study of transformations. ZDM, 34(3), 78-84.

Janela, M. A. C. P. (2012). O (novo) programa de Matemática do Ensino Básico e o desenvolvimento do raciocínio geométrico no tópico triângulos e quadriláteros: um estudo em turmas piloto do 7. ${ }^{\circ}$ ano. Tese de mestrado, Educação (Didáctica da Matemática), Universidade de Lisboa, Instituto de Educação.

Laborde C. (2005). The Hidden Role of Diagrams in Students' Construction of Meaning in Geometry. In: J. Kilpatrick, C. Hoyle, O. Skovsmose, P. Valero (eds.) Meaning in Mathematics Education (pp. 159-179). New York, NY: Springer. doi: https://doi.org/10.1007/0-387-24040-3_11

Matos, J. M. \& Gordo, M. F. (1993). Visualização espacial: algumas actividades. Educação e Matemática, 26, 13-17. 
JAHN, A.P.; BONGIOVANNI, V.

Pyke (2003). The use of Symbols, Words, and Diagrams as indicators of Mathematical Cognition: A Causal Model.
Journal for research in mathematics education, 34(5), 406432. 